computer. I should like to indicate two very excellent books by Minsky ${ }^{1}$ and Rogers ${ }^{2}$ which cover and expand much of Shepherdson's material.

The fine expository paper by Andrew takes in a large area of learning theory and systems while three of the other papers could be thought of as extended examples of points put forward by Andrew. With each of these erticles one finds that the predominant theme is that "human learning interlocks with problem solving, thinking and, above all, language", language boing taken as a point of utmost importance although so far grossly neglected by most learning theorists. George and Stewart mention that the ease of solution of problems depends on the problem being embedded in the right "problemspace". A recent article by Newell ${ }^{3}$ illustrates this point woll.

The other two papers, by Pask (about a third of the book) and Ross Ashby respectively, might have been better presented as short monographs in their own right. Pask's basic premise is that man needs to learn and is an active control system that cannot be turned off and isolated from the environment he controls. With this in mind he proposes the requirement for an experimental environment (the maintenance of which is delegated to a machine) such that the subject (man) acts as a self-organizing system. From this the general theoretical aspects are expounded in the first part of the paper. In the second half, experimental results are given for the case where the environmental machine is a teaching device. It might be as well to have studied Ashby's contribution to read the mathematics of Pask's paper. Ashby lays down a mathematical foundation, in terms of Bourbaki's algebraic set theory, suitable for a discussion of general systems theory. The style is terse and may not suit the uninitiated.

Although there is seemingly no cohesive force tying all the papers together this book should serve as a useful source for those interested in learning systems.

Charles Rattray

${ }^{2}$ Minsky, M., Computation: Finite and Infinite Machines (Prentice-Hall, 1967).

Rogers, H., Theory of Recursive Functions and Lffective Computability

3 Newell, A., On the Representation of Problems, Computer Science Research Review: An Annual Report (Carnegie-Mellon University, Pittsburgh USA, 1966).

\section{HEAT AND MASS TRANSFER}

\section{Thermophysical Properties Research Literature Retrieval} Guide

Edited by Y. S. Touloukian, J. K. Gerritsen and N. Y. Moore. Second edition, revised and expanded. Book 1: Pp. xxi+819. Book 2: Pp. 621. Book 3: Pp. ix +1315. (New York: Plenum Press, 1967.) n.p.

THE acquisition of reliable data often presents a major problem to engineers and scientists who require know. ledge of the physical properties of materials in any tem. perature range. Although the required data may have been published, a quick search in a fow abstracting journals often fails to yield the desired information because it is hidden away in governmental and industrial reports. Consequently, any aid to locating all the literature of a particular field should be warmly welcomed.

The work under review covers the following transport and thermodynamic properties encountered in heat and mass transfer calculations--thermal conductivity (including accommodation coefficient and contact resistance), thermal diffusivity, diffusion coefficient, specific heat, viscosity, thermal radiativo propertios, and Prandtl number. This publication is the third volume of a series and, in addition to updating the set, it also includes the information contained in the oarlier volumos, each of which covered references from different and mixed chronological periods. Volume 3 therefore claims to cover virtually all relevant information publishod in the world up to July 1964; a few of the more important references from 1965 are also included. In essence, the three books comprising volume 3 are a print-out of a specially devised computer programme which leads tho user to references on the properties listed earlier. The search starts in the first book, which is mainly a classified directory of all substances, and which indicatos whother any information is available on the required property. This leads to the second book, which is arranged under property headings and usefully reveals whether the re. quired subject matter (theoretical, experimental, and so on), physical state (gas, liquid, solid), temperature range, and year of interest may be found in the master bibliography of the third book. The 139,305 reference entries given in book 3 certainly offer the widest possible coverage because they are drawn not only from scientific and technical journals but also from university dissertations and the reports of government agencies, industrial organizations and research centres.

The substance classification in book 1 gathers materials into similar classes by their chemical composition. Although most substances are easily located, it is neces. sary to know the chemical composition of many alloys and compounds before the search can begin. A dictionary of synonyms and trade names is included in book 1 for those materials which are known by more than one name, but it does not always record every class grouping for a particular material. For example, the dictionary of synonyms suggests that yttrium iron garnet is listed as yttrium ferrate in group 110 (elements and their com. pounds), but does not mention that it is also listed as garnet (iron yttrium) in group 521 (minerals). Group 521 yields a reference for the specific heat which is different from any of the five references derivod from group 110 for the same property. This underlines the advice given in the instructions that the search should be made in more than one class of material. The classification of the ferrous and non-ferrous alloys is remarkable in giving the precise composition of each alloy recorded. The time taken to complete a search, however, could have been made even shorter if those alloys with specific titles (Nimonics, for example) had been included in the dictionary of trade names. A point worth remembering is that a substance is classed as an element if the total impurity content is less than 0.5 weight per cent and individual impurities do not exceed 0.2 weight per cent each; outside these limits the material is classed as an alloy. This means that the well-known "Armco Iron" is not mentioned at all by name but is included in the references for elemental iron; it would again have been useful if this had been noted in the dictionary of trade names.

The "Retrieval Guide" contains forty times more references than the data books originating from the same source (TPRC) and, apart from the foregoing observations, all pertinent references from the world literature can be found quickly and easily. With the promise of further volumes to keep the series up to date, this work should prove invaluable to all workers in the fields of heat and mass transfer.

M. J. WHEELER

\section{SCIENCE AS POLITICS}

\section{Science and Technology in British Politics}

By Norman J. Vig. Pp. ix +190 . (London and Now York: Pergamon Press, 1968.) 458.

Now that the British Government has decided not to support the CERN $300 \mathrm{GoV}$ machine, it is easy to forget that the Labour Party once claimed to be the party of science. But in 1963 and 1964, when the party leadership suddenly stumbled on science, things wore different. There was talk of the technological revolution, of re- 